\title{
Successful infection of BALB/c mice by a swine hepatitis $E$ virus clone constructed with reverse genetics
}

\author{
Wenhai $\mathrm{Yu}^{1}$, Chenchen $\mathrm{Yang}^{2}$, Xianhui Hao ${ }^{2}$, Tianwu $\mathrm{Ma}^{2}$ and Fen Huang ${ }^{2 *}$ (I)
}

\begin{abstract}
Background: Hepatitis E virus (HEV) is a leading cause of hepatitis worldwide. However, its infection biology and pathogenesis remain largely elusive. Furthermore, no proven medication is available for treating hepatitis E. Robust experimental models are urgently required to advance the research of HEV infection. Because of the lacking of a sophisticated small animal model, this study aimed to establish a mouse model of HEV infection.

Methods: We constructed a full-length swine HEV CDNA clone of genotype 4 (named as pGEM-HEV) by reverse genetics approach. And we inoculated with HEV RNA in BALB/c mice to establish small animal model for HEV infection and pathogenesis studies.

Results: The capped RNA transcripts of pGEM-HEV prepared in vitro were replication-competent in HepG2 cells. Importantly, BALB/c mice intravenously inoculated with RNA transcripts of pGEM-HEV developed an active infection as shown by shedding viruses in feces, detectable negative strand of HEV in the liver, spleen and kidney, and causing liver inflammation.

Conclusion: In this study, we successfully established of BALB/c mice-based small animal model for HEV provides an opportunity to further understand HEV pathogenesis and to develop effective antiviral medications.
\end{abstract}

Keywords: Hepatitis E virus, Infectious cDNA clone, BALB/c mice, Infectivity

\section{Background}

Hepatitis E virus (HEV) is classified in the genus Orthohepevirus of the family Hepeviridae [1]. It is a non-enveloped, single-stranded, positive-sense RNA virus, with an approximately $7.3 \mathrm{~kb}$ genome. The viral genome consists of three open reading frames (ORFs) flanked by short $5^{\prime}$ and $3^{\prime}$ non-translated regions, ORF1 encodes a nonstructural protein, ORF2 encodes a capsid protein and ORF3 encodes a small multifunction protein that is essential for viral infection [2-5]. A unique feature as a hepatitis virus is that HEV has a zoonotic nature and can cross-species transmit in human, swine and deer [6-10].

HEV is considered the most common cause of hepatitis worldwide [11]. It causes both endemic and epidemic forms of hepatitis E in many developing countries. It is transmitted

\footnotetext{
*Correspondence: huangfen6789@163.com

${ }^{2}$ Medical School, Kunming University of Science and Technology, 727

Jingming Road, Kunming, China

Full list of author information is available at the end of the article
}

by the fecal-oral route and waterborne transmission is most often described. In developed countries, most documented cases of acute hepatitis E are sporadic and endemic cases attributed to food consumption [11-13]. Although the infection is generally acute and self-limiting, up to about $25 \sim 30 \%$ mortality has been reported following HEV infection during pregnancy $[14,15]$. However, the biology and pathogenesis of HEV infection remain largely elusive and no proven antiviral medication is available.

Robust experiment models are the most important tools for advancing fundamental and translational research of hepatitis E infection. Fortunately, several cell culture systems for propagating HEV have been recently developed [16-18]. However, the development of animal models, in particular the use of small laboratory animals, has not been well-explored. Although swine and rabbit have been used to model HEV infection $[19,20]$, experimental infection in mouse model, the most commonly used laboratory species, has not been established. 
We previously have attempted to establish $\mathrm{BALB} / \mathrm{c}$ nude mice-based HEV model [21]. However, this strain lacks a thymus and is therefore unable to produce T-cells. The immunodeficient nature with a strict life condition and limited fertility has hampered the further application. To circumstance these bottlenecks, this study aimed to establish regular BALB/c mice-based HEV model. We first constructed an infectious cDNA clone of swine HEV with reverse genetics approach. We demonstrated its infectivity in cell culture and importantly also in BALB/c mice. Most interestingly, HEV provokes host response with production of anti-HEV antibodies and induction of liver inflammation, mimicking infection in human. Therefore, this model bears important implications for studying HEV infection and drug development.

\section{Methods}

\section{Construction of a full-length CDNA clone of HEV}

The full-length of swine HEV (genotype 4, KM01, GenBank No. KJ155502) was amplified with specific primers shown in Table 1 [22]. The collection of stool specimens was approved by the owner. Five overlapping fragments were amplified by PCR. The $3^{\prime}$ end and $5^{\prime}$ end of the virus were obtained using the RACE 5 ' or $3^{\prime}$ kit (Takara). The entire viral genome was ligated together at indicated restriction enzyme sites in each fragment (Fig. 1). A unique $X b a$ I restriction enzyme site and a T7 RNA polymerase core promoter were introduced at the extreme $5^{\prime}$ terminus. Twenty-four adenosines (A) was engineered at the 3 ' end of viral genome, followed by a Cla I restriction enzyme site for plasmid linearization (Fig. 1). PCR productions were purified and cloned into pMD-18 $\mathrm{T}$ vector, followed by sequencing with three clones of each fragment. The clone containing the consensus sequence was used for infectious clone assembly. One silent mutation at nucleotide (nt) $4120(\mathrm{G} \rightarrow \mathrm{T})$ generated during the PCR amplification was retained as a genetic marker. The full-length genomic cDNA was introduced into the pGEM-7zf $(+)$ vector (Promega) between $\mathrm{Xba}$ I and $\mathrm{Cla}$ I sites to produce a full-length HEV cDNA clone named pGEM-HEV.

\section{In vitro transcription of capped full-length HEV genomic RNA}

The full-length cDNA clones of pGEM-HEV was linearized by $\mathrm{Cla} \mathrm{I}$, then digested with proteinase $\mathrm{K}$, and purified by phenol extraction followed by ethanol precipitation. Capped RNA transcripts from pGEM-HEV were synthesized in vitro with the T7 RiboMAX ${ }^{\mathrm{Tn}}$ Express Large Scale RNA Production System (Promega, USA) according to the direction. The RNA transcripts from the cDNA clone was quantitated $(1 \mu \mathrm{g} / \mu \mathrm{L})$ and stored in $-80^{\circ} \mathrm{C}$ until use.
Cell transfection and immunofluorescence assay

The human hepatoma HepG2 cells and human lung carcinoma A549 cells were incubated at $37^{\circ} \mathrm{C}$ with $5 \% \mathrm{CO}_{2}$ in Dulbecco's modified eagle medium (DMEM) with $10 \%$ fetal bovine serum (FBS). To evaluate the infectivity of the pGEM-HEV clone, HepG2 (60 70\% confluence) cells were transfected with the capped RNA transcripts as described previously [19]. Twenty-four hours post-transfection, the cells were fixed and stained with a HEV-specific antibody (Merck Millipore, MAB8003, German, 1:1000 dilution). Briefly, cells were fixed with $4 \%$ paraformaldehyde for 15 min at $37^{\circ} \mathrm{C}$ and subsequently washed three times and incubated with $\mathrm{HEV}$ antibody for $60 \mathrm{~min}$ at $37^{\circ} \mathrm{C}$. Cells were washed three times with PBS (phosphate buffered saline) and incubated with FITC (fluorescein isothiocyanate) conjugated goat anti-mouse $\operatorname{IgG}(\mathrm{H}+\mathrm{L})$ antibody (Promega, USA, 1:1000 dilution) for $45 \mathrm{~min}$ at $37^{\circ} \mathrm{C}$. Nuclei were counterstained with 4',6-diamidino-2-phenylindole (DAPI). Cells were washed three times with PBS, and viewed under a fluorescence microscopy (Nikon Ti-E, Japan).

\section{Inoculation of BALB/c mice with capped RNA transcripts}

The protocol of animal experiments were approved by the Animal Care and Use Committee (ACUC) of Kunming University of Science and Technology. Six female, 8-week-old, SPF (specific pathogen free) $\mathrm{BALB} / \mathrm{c}$ mouse purchased from SLAC laboratory animal (China), and maintained in a pathogen-free animal facility. Mice were negative to anti-HEV IgG and IgM antibodies, and HEV RNA. Six mice were randomly divided into 2 groups and each mouse was caged separately.

Group A containing Mouse 1, 2 and 3 were inoculated with RNA transcripts of the swine HEV clone pGEM-HEV $(10 \mu \mathrm{g} /$ mouse), and Group B containing mouse 4, 5 and 6 were inoculated with equal volume PBS. Feces and serum were collected every week from each mouse after inoculation. Mice were anaesthetized with pentobarbital $(80 \mathrm{mg} / \mathrm{kg})$ and euthanized by cervical dislocation at 28 days post-inoculation (dpi). Tissues, including liver, spleen, kidney and colon were collected. Animal carcasses were safely disposed by the ACUC of the Kunming University of Science and Technology (WH17037).

\section{Detection of HEV RNA in feces, serum and tissues by nested RT-PCR and quantitative RT-PCR}

Total RNA in feces, serum and tissues were extracted by Trizol (Invitrogen), according to the manufacturer's instructions. The isolated RNA was used to synthesize first-strand cDNA. The cDNA was added as the template to perform the reverse transcription nested PCR (RT-nPCR). Both positive strand and (or) negative strands 
Table 1 Primers sequence

\begin{tabular}{|c|c|c|c|c|}
\hline Primer ID & Sequence $\left(5^{\prime} \sim 3^{\prime}\right)$ & Product & Length (bp) & Reference \\
\hline$S 11$ & AGGCTCCTGGCRTYACTACTG & F1 & $1163 \mathrm{bp}$ & 2 \\
\hline S12 & GCCYTGGCGAATGCTGTG & & & \\
\hline A11 & GGCCRGGAATGTAATCACG & & & \\
\hline $\mathrm{A} 12$ & GCGGCACTGGGCRTAAAACT & & & \\
\hline HEV-A1 & AAAGGAATGAAGAGGCTGGAG & F2 & $1520 \mathrm{bp}$ & This study \\
\hline HEV-A3 & GAAAAGTCTGGCCGTGATTAC & & & \\
\hline HEV-B2 & TCCTCAGTAATAGTAAGGGC & & & \\
\hline HEV-B4 & AGGTCGATGGTTACGTTCCC & & & \\
\hline HEV-C1 & TGCCTGTTGGGCTGAGTTTTGATG & F3 & 1394 bp & This study \\
\hline HEV-C3 & GCCAGCCATAGCTTGGTTTGAAG & & & \\
\hline D1R & AAGGTCTTGCTCCACGCAGATATC & & & \\
\hline D3R & CTGGAAGAATGTTATACGAGACAC & & & \\
\hline $\mathrm{D} 2 \mathrm{~F}$ & CTTGTGGAGGCCATGGTGGAGAA & F4 & $1243 \mathrm{bp}$ & This study \\
\hline D4F & ATGGTGGAGAAAGGCCAGGAT & & & \\
\hline ER1 & TCACGCCAAGCGGAGCCGAGT & & & \\
\hline ER2 & GAAGGGGTTGGTTGGATGAAT & & & \\
\hline EF1 & TTTCTGGGGTGACCGGGTTGATT & F5 & $1791 \mathrm{bp}$ & This study \\
\hline EF2 & СТATATTCATCCAACCAACCCCT & & & \\
\hline HEV31 & CAGGGAGCGCGGAACGCAGAAAAGA & & & \\
\hline HEV32 & TCAATACTCCCGAGTTITACCCACC & & & \\
\hline 5' Race-A1 & GCAGTGARTARAGYGCAAYCCCHGTCT & 5' RACE & $501 \mathrm{bp}$ & 2 \\
\hline 5' Race-A2 & CGRGCCATYGCCTCNGCRACATC & & & \\
\hline 3' Race-S1 & ACYACNACTGCTGCYACACGBTTYATGA & 3' RACR & $936 \mathrm{bp}$ & 2 \\
\hline 3' Race-S2 & CTYTGTTYAAYCTTGCTGAYACGCTKCTC & & & \\
\hline T7P1 & GCCTAGCTAGCTAGTCTAGATAATACGACTCACTATA & $5^{\prime}$ terminal & - & This study \\
\hline PAP2 & 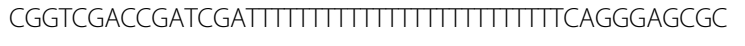 & $3^{\prime}$ terminal & - & This study \\
\hline HEV1 & AATTATGCC(T)CAGTAC(T)CGG(A)GTTG & Positive strand of HEV RNA & $348 \mathrm{bp}$ & {$[23]$} \\
\hline HEV2 & CCCTTA(G)TCC(T)TGCTGA(C)GCATTCTC & & & \\
\hline HEV3 & GTT(A)ATGCTT(C)TGCATA(T)CATGGCT & & & \\
\hline HEV4 & AGCCGACGAAATCAATTCTGTC & & & \\
\hline HEV6 & AGCTCCTGTACCTGATGATGTTGACTC & Negative strand of HEV RNA & $266 \mathrm{bp}$ & {$[24]$} \\
\hline HEV7 & CTACAGAGCGCCAGCCTTGATTGC & & & \\
\hline HEV8 & GCTCACGTCATCTGTCGCTGCTGG & & & \\
\hline HEV9 & GGGCTGAACCAAAATCCTGACATC & & & \\
\hline WHO-F & GGTGGTTTCTGGGGTGAC & qRT-PCR & 70 bp & {$[25]$} \\
\hline WHO-R & AGGGGTTGGTTGGATGAA & & & \\
\hline
\end{tabular}

of $\mathrm{HEV}$ in feces, serum and tissues were detected with strand-specific primers [23, 24] as described previously and shown in Table 1.

The viral titer of HEV in the feces, serum and tissues were quantified using SYBR green-based quantitative RT-PCR (qRT-PCR) with HEV-specific primers [25]. qRT-PCR was performed using the BIO-RAD CFX Connect Real-Time System under the following conditions: $95^{\circ} \mathrm{C}$ for $30 \mathrm{~s}$, followed by 39 cycles of $95^{\circ} \mathrm{C}$ for $5 \mathrm{~s}$ and $60^{\circ} \mathrm{C}$ for $31 \mathrm{~s}$.

\section{Determination of HEV antibodies by ELISA}

The HEV IgG and IgM antibodies in serum were tested by ELISA (KHB, China) according to the manufacturer's instructions. The cutoff values for the IgG and IgM 


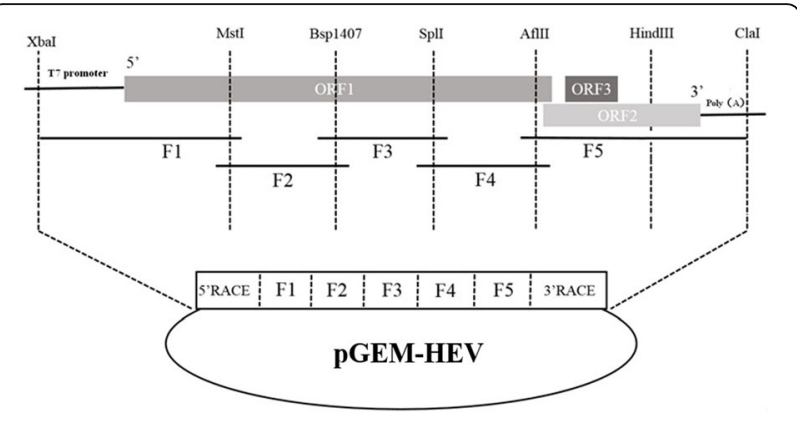

Fig. 1 A schematic diagram of the strategy used to assemble the full-length cDNA clone of swine HEV

assay were determined based on 0.22 (or 0.24 for IgM) plus the mean OD450/630 values of serum from uninfected mouse ( \pm standard deviation, S. D.).

\section{Profile liver biochemistry in serum}

The activities of alanine aminotransferase (ALT), aspartate aminotransferase (AST) and alkaline phosphatase (ALP) in serum were measured with an automated biochemistry analyzer (Olympus 2700, Japan).

\section{Detection of HEV ORF2 protein in tissues by Western blotting}

The livers, spleens, kidneys and colons were collected and HEV capsid protein were detected in these tissues by Western blotting. Briefly, the tissues were broken in liquid nitrogen by grinding, and were lysed in RIPA buffer. Equal volumes of tissue lysates from each condition were resolved by $10 \%$ sodium dodecyl sulfate-polyacrylamide gel electrophoresis (SDS-PAGE). Analysis of protein was visualized by direct Western blotting using antibodies directed against the indicated antigens.
Infection of A549 cells with viruses recovered from mouse inoculated with capped RNA transcripts of swine HEV clones

The mouse feces were suspended into 0.1\% DEPC (diethyl pyrocarbonate)-PBS. The supernatant was collected by centrifuge and microorganisms were removed by filter. A549 cells were infected with the viruses recovered from mice experimentally infected with feces supernatant. Cells were harvested at $72 \mathrm{~h}$ post-infection, and the HEV ORF2 protein was be detected by Western blotting.

\section{Histopathologic examination}

The liver tissues were fixed in $10 \%$ neutral buffered formalin, sectioned at a thickness of $3 \mu \mathrm{m}$, and stained with hematoxylin and eosin. All sections were examined using a Nikon Ti-E microscope (Japan).

\section{Statistical analysis}

Prism software (GraphPad Software) was used for statistical analysis. Data were presented as mean \pm S. D.

\section{Results}

A full-length CDNA clone of swine HEV is infectious

To assess the infectivity of the pGEM-HEV cDNA clone, capped RNA transcripts were transfected into HepG2 cells. Twenty-four hours post-transfection, HEV antigens were detected by immunofluorescence assay (IFA) with an anti-HEV ORF2 monoclonal antibody. The intense fluorescent signals of HEV antigens indicating that the transfected viral RNA was replication-competent in HepG2 cells (Fig. 2). The fluorescent signal was detected in HepG2 cells transfected with the capped RNA transcripts, while no signal in non-tranfected control cells.

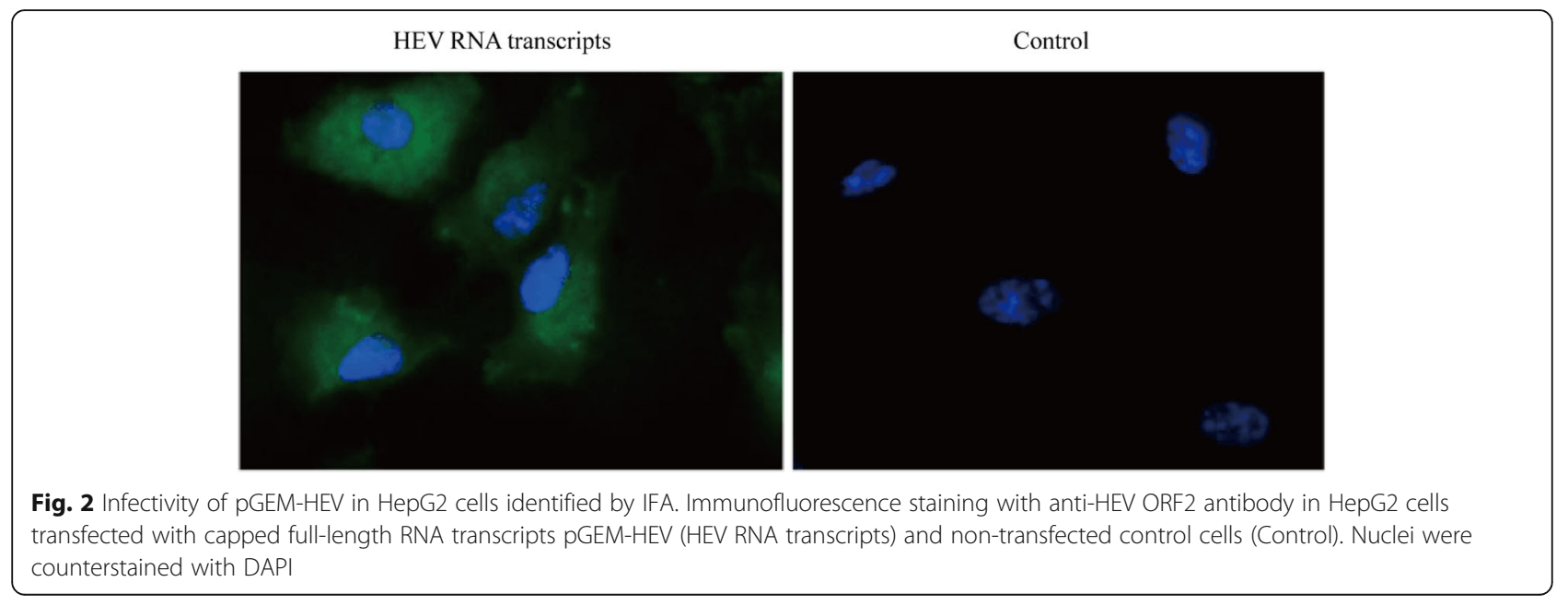




\section{Capped RNA transcripts of pGEM-HEV was infectious in BALB/c mice}

To further investigate whether this clone can be used to establish infection in mice, we explored the infection in BALB/C mouse model. Mice in groups $\mathrm{A}$ and $B$ were intravenously injected with full-length capped RNA transcripts from pGEM-HEV (HEV RNA transcripts) and PBS (Control), respectively. HEV RNA was first detected in feces at 3 dpi in group A inoculated with RNA transcripts, and it was all detected in feces from three mice feces after $7 \mathrm{dpi}$, and lasted to the end of the experiment (Table 2). The viral titer of HEV in the feces of mice inoculated with HEV RNA transcripts was detected from 3 to 28 dpi (Fig. 3a). In the serum, HEV RNA positive-strands were all detected in mice inoculated with RNA transcripts from 7 to 28 dpi (Fig. 3b). The HEV negative-strand RNA was detected in one mouse at $7 \mathrm{dpi}$ and two mice at $14 \mathrm{dpi}$ in group A inoculated with RNA transcript, and all detected at $21 \mathrm{dpi}$. However, mice injected

Table 2 Detection of HEV RNA by RT-nPCR in feces, serum and tissues of mouse inoculated with capped full-length RNA transcripts of pGEM-HEV or PBS

\begin{tabular}{|c|c|c|c|c|}
\hline \multicolumn{2}{|l|}{ Sample } & \multirow{2}{*}{$\begin{array}{l}\text { Strand } \\
\text { Positive }\end{array}$} & \multirow{2}{*}{$\begin{array}{l}\text { HEV RNA transcripts } \\
-\end{array}$} & \multirow{2}{*}{$\begin{array}{l}\text { Control } \\
-\end{array}$} \\
\hline Feces & 0 dpi & & & \\
\hline & $3 \mathrm{dpi}$ & Positive & $+(1 / 3)$ & $+(0 / 3)$ \\
\hline & 4 dpi & Positive & $+(2 / 3)$ & $+(0 / 3)$ \\
\hline & $7 \mathrm{dpi}$ & Positive & $+(3 / 3)$ & $+(0 / 3)$ \\
\hline & $14 \mathrm{dpi}$ & Positive & $+(3 / 3)$ & $+(0 / 3)$ \\
\hline & $21 \mathrm{dpi}$ & Positive & $+(3 / 3)$ & $+(0 / 3)$ \\
\hline & $28 \mathrm{dpi}$ & Positive & $+(3 / 3)$ & $+(0 / 3)$ \\
\hline \multirow[t]{10}{*}{ Serum } & $0 \mathrm{dpi}$ & Positive & $+(0 / 3)$ & $+(0 / 3)$ \\
\hline & & Negative & $+(0 / 3)$ & $+(0 / 3)$ \\
\hline & 7 dpi & Positive & $+(3 / 3)$ & $+(0 / 3)$ \\
\hline & & Negative & $+(1 / 3)$ & $+(0 / 3)$ \\
\hline & $14 \mathrm{dpi}$ & Positive & $+(3 / 3)$ & $+(0 / 3)$ \\
\hline & & Negative & $+(2 / 3)$ & $+(0 / 3)$ \\
\hline & $21 \mathrm{dpi}$ & Positive & $+(3 / 3)$ & $+(0 / 3)$ \\
\hline & & Negative & $+(3 / 3)$ & $+(0 / 3)$ \\
\hline & $28 \mathrm{dpi}$ & Positive & $+(3 / 3)$ & $+(0 / 3)$ \\
\hline & & Negative & $+(2 / 3)$ & $+(0 / 3)$ \\
\hline \multirow[t]{8}{*}{ Tissues } & Liver & Positive & $+(3 / 3)$ & $+(0 / 3)$ \\
\hline & & Negative & $+(3 / 3)$ & $+(0 / 3)$ \\
\hline & Spleen & Positive & $+(3 / 3)$ & $+(0 / 3)$ \\
\hline & & Negative & $+(3 / 3)$ & $+(0 / 3)$ \\
\hline & Kidney & Positive & $+(2 / 3)$ & $+(0 / 3)$ \\
\hline & & Negative & $+(2 / 3)$ & $+(0 / 3)$ \\
\hline & Colon & Positive & $+(0 / 3)$ & $+(0 / 3)$ \\
\hline & & Negative & $+(1 / 3)$ & $+(0 / 3)$ \\
\hline
\end{tabular}

with PBS were negative to both positive and negative strands during the whole experiment.

Replication of HEV in multiple tissues, including liver, spleen, kidney and colon, has been reported in both pigs and nude mice when inoculated with $\operatorname{HEV}[21,26]$. In order to further analyze the replication of HEV in different tissues, HEV genome RNA and capsid protein (ORF2) were analyzed by RT-nPCR, qRT-PCR and Western blotting, respectively. In the present study, HEV RNA was detected with a high viral titer in the liver $\left(6.2 \times 10^{5} \pm 5.8 \times 10^{4}\right.$ copies/g), spleen $\left(1.3 \times 10^{4} \pm 3.7 \times 10^{4}\right.$ copies/g), kidney $\left(7.1 \times 10^{4} \pm 3.1 \times 10^{4}\right.$ copies/g) and colon $\left(1.9 \times 10^{4} \pm 5.8 \times 10^{3}\right.$ copies/g) of mice inoculated with HEV RNA transcripts at $28 \mathrm{dpi}$ (Fig. 3c). HEV RNA (both positive and negative strands) were detected in the liver and spleen in mice inoculated with HEV RNA transcripts at $28 \mathrm{dpi}$ (Table 2). Although colon has been reported as a replicate site of HEV [21], only one mouse inoculated with HEV RNA transcripts at 28 dpi was found to be positive (Table 2). Meanwhile, the capsid protein of HEV (ORF2) were detected in the liver, spleen and kidney of mice inoculated with HEV RNA transcripts (Fig. 3d-g) by Western blotting. Shedding viruses in the feces, detected HEV RNA antigens in the serum and tissues indicated that HEV RNA transcripts was infectious in $\mathrm{BALB} / \mathrm{c}$ mice.

\section{$B A L B / c$ mice produce infectious HEV viruses upon inoculation of capped RNA transcripts of the swine HEV clone}

To confirm whether BALB/c mice can produce infectious $\mathrm{HEV}$ viruses, we attempted to infect A549 cells with the recovered viruses from mice inoculated with capped RNA transcripts of the swine HEV clone. A549 cells were harvested $72 \mathrm{~h}$ after infection. HEV capsid protein was detected by Western blotting (Fig. 4) in cells infected with the feces of BALB/c mice inoculated with HEV RNA transcripts. This result confirmed that the inoculated BALB/c mice can produce infectious HEV, which can replicate in A549 cells.

\section{Capped RNA transcripts of pGEM-HEV provokes humoral response in $\mathrm{BALB} / \mathrm{c}$ mice}

In response to HEV infection, human body develops antibodies to HEV (IgM and IgG). To investigate whether BALB/c mice provoke similar response to RNA transcripts of HEV infection, we measured serum anti-HEV IgM and IgG. An increased anti-HEV IgM and IgG levels were observed in all the mice inoculated with HEV RNA transcripts compared with the control group (Fig. 5). In the RNA transcripts inoculated group, the increased IgM level reached the pink at $21 \mathrm{dpi}$. IgG began to increase at 


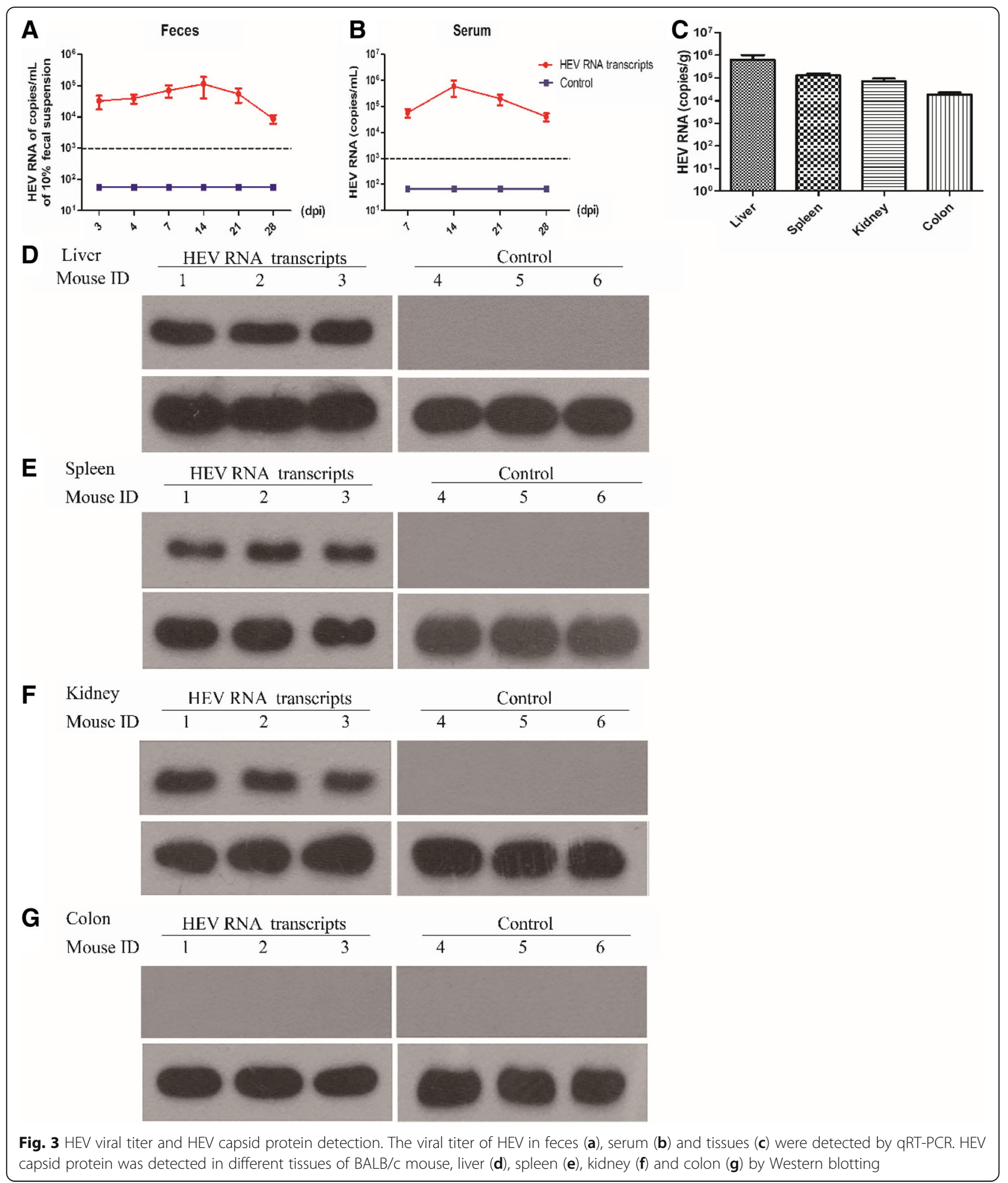

$21 \mathrm{dpi}$, and continued to increase until the end of the experiment. These results demonstrated that infection of the swine HEV infectious clone stimulated humoral response in $\mathrm{BALB} / \mathrm{c}$ mice.
Infection of capped HEV RNA transcripts induces liver inflammation in BALB/c mice

Hepatitis is swelling and inflammation of the liver, and most commonly caused by hepatitis virus infections. To 


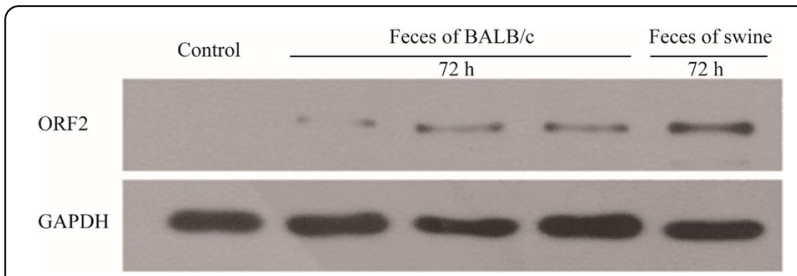

Fig. $4 \mathrm{BALB} / \mathrm{C}$ mice produce infectious HEV viruses upon inoculation of capped RNA transcripts of the swine HEV clone. A549 cells were infected with the feces suspension of BALB/C mouse inoculated with HEV RNA transcripts. Cells were harvested at $72 \mathrm{~h}$ post-inoculation to detect ORF2 protein by Western blotting. The feces suspension of swine HEV served as positive control. GAPDH served as a loading control

determine whether infection of capped HEV RNA transcripts can also cause liver injury/inflammation in $\mathrm{BALB} / \mathrm{c}$ mice, we first tested the widely used liver enzymes for detecting liver damage. The levels/activities were characterized using an automated biochemistry analyzer. To our surprise, the elevated ALT, AST and ALP levels/activities in BALB/c inoculated with $\mathrm{HEV}$ RNA transcripts was very similar to the clinical feature of HEV infected patients (Fig. 6a, b and c).

Furthermore, histopathologic examination showed swelling of liver cells and liver capsules were filled with inflammatory exudates and liver hemorrhage in mice inoculated with RNA transcripts of HEV (Fig. 6d). Increased infiltrating lymphocytes and macrophages were observed in these mice. In contrast, no damage was observed in any of the control tissues. These results indicate that infection of swine HEV RNA transcripts triggered liver inflammation in BALB/c mice.

\section{Discussions}

Lessons from the research of hepatitis $\mathrm{B}$ and $\mathrm{C}$ viruses have taught us the importance of developing robust experimental models for understanding their infection biology, pathogenesis, as well as antiviral drug development. However, the restricted tropism of host and cell type for hepatitis virus infection has always challenged the development of experimental

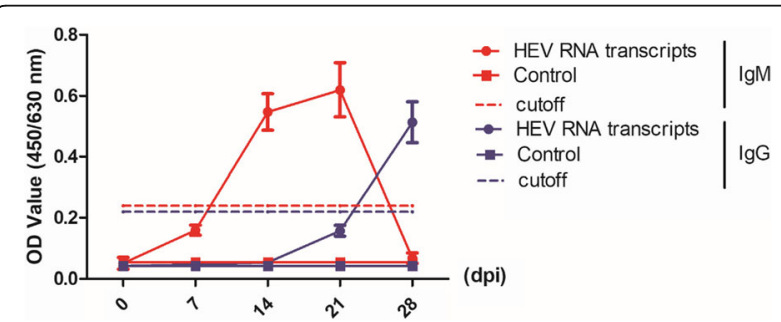

Fig. 5 Anti-HEV IgM and IgG antibodies in BALB/C mouse were tested by ELISA. Anti-HEV IgM and IgG antibodies in BALB/C mouse inoculated with HEV RNA transcripts or PBS were tested by ELISA models. Despite the recent establishment of several cell culture systems of HEV [27], animal models are urgently need for studying $\mathrm{HEV}$ pathogenicity and antiviral drug development.

Non-human primates have been successfully employed for HEV research in early days [28, 29], but non-human primates are not available for research anymore, because of the ethics. Although swine is the mainly reservoir of HEV, it is not suitable as an experimental model for HEV because of its large body size. In contrast, mice are the most commonly used small animal for research purpose. This study, we reported the successful establishment of HEV infection in BALB/c mice with an infectious swine HEV clone generated by reverse genetics approach.

In fact, we have previously attempted to establish HEV mouse model using BALB/c nude mice [21]. Because nude mice lack the thymus and are therefore unable to produce T-cells. We thought that the immunodeficient nature of these mice could be an advantage of permitting $\mathrm{HEV}$ infection. Indeed, we have succeeded the infection in BALB/c nude mice with genotype 4 swine HEV strain [21]. However, the immunodeficient property in turn hampered the study of HEV pathogenesis. Because hepatitis is an inflammatory process mainly mediated by host immune response. Furthermore, these mice have a strict life condition and limited fertility, which also hampers the further application. To circumstance these limitations, we now have succeeded with infecting the regular BALB/c mice, which have a competent immune system. In the present study, the RNA transcripts of infectious cDNA clone of swine HEV was successfully infected BALB/c mice. HEV RNA was detected at 3 dpi in feces, which is similar to our genotype 4 swine $\mathrm{HEV}$ strain inoculated into BALB/c nude mice [21], but earlier than that inoculated pigs with genotype 4 swine HEV RNA transcripts (7 dpi) [20] and Sprague-Dawley rat (SD rat) inoculated with genotype 4 swine HEV RNA transcripts [30]. HEV produces an intermediate negative-strand RNA when it replicates. The negative-strand of $\mathrm{HEV}$ was detectable at $7 \mathrm{dpi}$ in serum of all mice inoculated with RNA transcripts. Furthermore, the negative-strand was found in the HEV replicated sites, including liver (3/3), spleen (3/ $3)$, kidney (2/3) and colon (1/3). Moreover, HEV RNA was detected in the feces, serum and tissues (liver, spleen, kidney and colon). Shedding HEV in feces, and detection of negative-strand RNA in liver, spleen and kidney firmly demonstrated the infectivity of the genotype 4 swine $\mathrm{HEV}$ pGEM-HEV cDNA clone is infectious in $\mathrm{BALB} / \mathrm{c}$ mice, although previous study reported that $\mathrm{C} 57 \mathrm{BL} / 6$ mice is not permissive for HEV infection [31]. More interestingly, we observed 


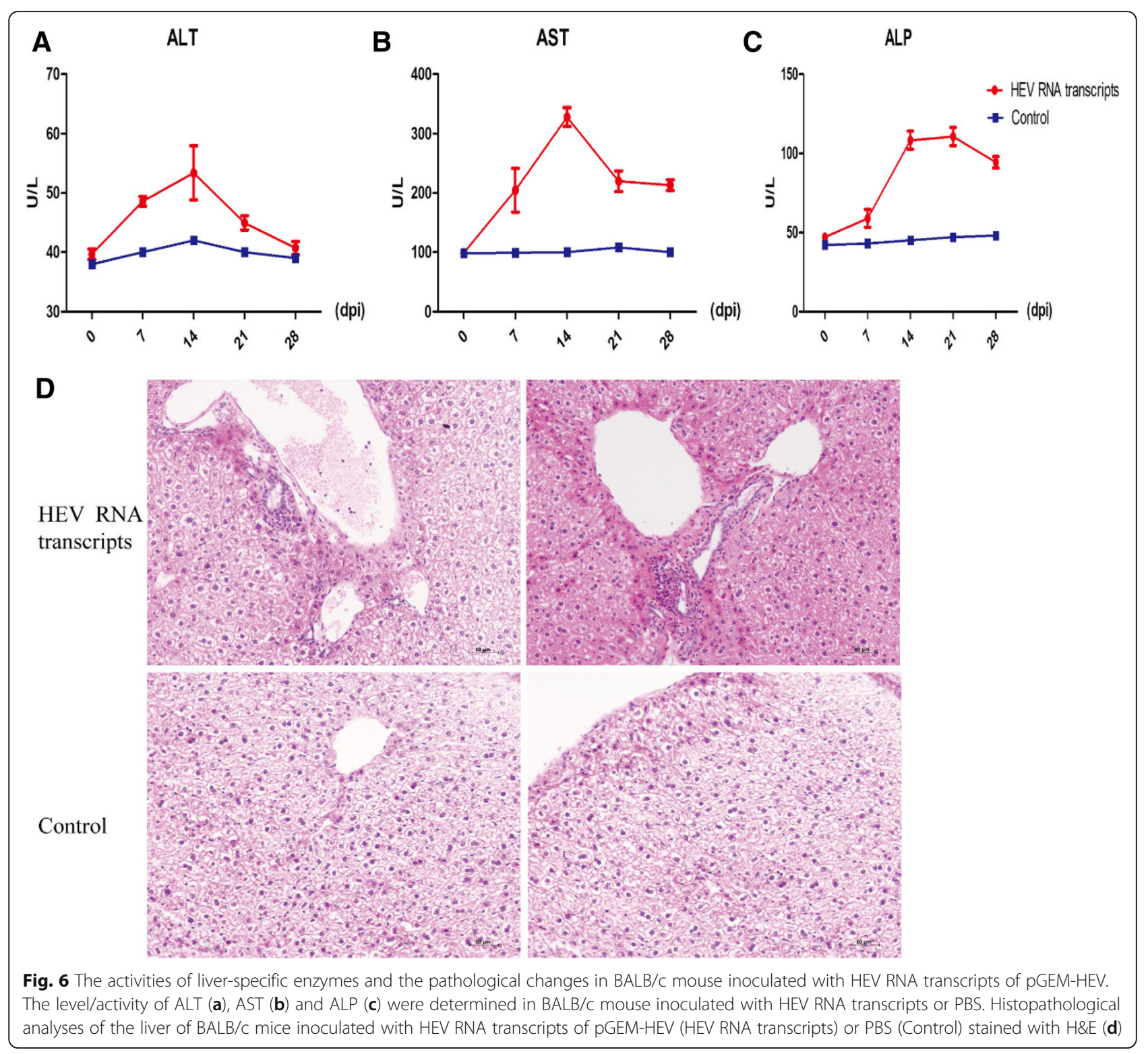

humoral response and liver injury in infected BALB/c mice, indicating that this model is promising for studying HEV pathogenesis.

Although $\mathrm{HEV}$ infects $\mathrm{BALB} / \mathrm{c}$ mice has been successfully established, key parameters should be determined in the future, such as identification of infected cell populations, observation of inflammatory manifestation, and then explicit comparisons with HEV infected patients to assess potential for clinical relevance. The establishment of HEV infection based on $\mathrm{BALB} / \mathrm{c}$ mice is benefit to screen anti-HEV drugs and develop vaccines in vivo.

\section{Conclusion}

In this study, we successfully established BALB/C mice-based animal model with an infectious cDNA clone of genotype 4 swine HEV constructed by reverse genetics approach. This swine HEV clone strain is capable of modeling HEV infection, and studying host response and pathogenesis. Furthermore, this model also bears importantly implications for future anti-HEV drug development.

\section{Abbreviations}

A549 cells: Human lung carcinoma cell line; ACUC: Animal Care and Use Committee; ALP: Alkaline phosphatase; ALT: Alanine aminotransferase; AST: Aspartate aminotransferase; ATCC: American Type Culture Collection; DAPI: 4',6-diamidino-2-phenylindole; DEPC: Diethyl pyrocarbonate; DMEM: Dulbecco's modified eagle medium; dpi: days post-inoculation; ELISA: Enzyme-linked immunosorbent assay; FBS: Fetal bovine serum; FITC: Fluorescein isothiocyanate; HepG2 cells : Human hepatocellular carcinoma cell line; HEV: Hepatitis E virus; IFA: Immunofluorescence assay: IgG: Immunoglobulin G; IgM: Immunoglobulin M; ORFs: Open reading frames; PBS: Phosphate buffered saline; qRT-PCR: quantitative real time PCR; RACE: Rapid Amplification of cDNA Ends; RT-nPCR: Reverse transcription nested PCR; S. 
D.: Standard deviation; SD rat: Sprague-Dawley rat; SDS-PAGE: Sodium dodecyl sulfate-polyacrylamide gel electrophoresis; SPF: Specific pathogen free

\section{Acknowledgements}

Authors thank Xiancheng Zhao for her contribution on HEV full-length genome amplification, and Ping Yan for his contribution on sample collection

\section{Funding}

This study was supported by National Natural Science Foundation of China (grant number 31360619 and 81660338 to Fen Huang), Natural Science Foundation of Yunnan province (grant number 2017 FA036 to Fen Huang and 2018FB132 to Wenhai Yu), Fundamental Research Funds for the Central Universities (grant number 2016ZX310179) and PUMC Youth Fund (grant number 2017310038) to Wenhai Yu. The funders had no role in study design, data collection and analysis, decision to publish, or preparation of the manuscript.

\section{Availability of data and materials}

All data generated or analyzed during this study are included in this published article.

\section{Authors' contributions}

WY, CY, XH and TM performed the experiment; FH, CY and WY wrote the manuscript. All authors contributed to the analysis and interpretation of data. All authors have read and approved the manuscript, and ensure that this is the case.

\section{Ethics approval}

The animal protocol was approved by the Animal Care and Use Committee (ACUC) of the Kunming University of Science and Technology.

\section{Consent for publication}

Not applicable

\section{Competing interests}

The authors declare that they have no competing interests.

\section{Publisher's Note}

Springer Nature remains neutral with regard to jurisdictional claims in published maps and institutional affiliations.

\section{Author details}

'Institute of Medical Biology, Chinese Academy of Medical Sciences and Peking Union Medical College, 935 Jiaoling Road, Kunming, China. ${ }^{2}$ Medical School, Kunming University of Science and Technology, 727 Jingming Road, Kunming, China.

Received: 24 April 2018 Accepted: 23 November 2018 Published online: 20 December 2018

\section{References}

1. Smith DB, Simmonds P, Jameel S, Emerson SU, Harrison TJ, Meng XJ, Okamoto $\mathrm{H}$, Van der Poel WH, Purdy MA. Consensus proposals for classification of the family Hepeviridae. J Gen Virol. 2014;95(Pt 10):2223-32.

2. Billam P, Sun ZF, Meng XJ. Analysis of the complete genomic sequence of an apparently avirulent strain of avian hepatitis E virus (avian HEV) identified major genetic differences compared with the prototype pathogenic strain of avian HEV. J Gen Virol. 2007:88(Pt 5):1538-44.

3. Panda SK, Nanda SK, Zafrullah M, Ansari IH, Ozdener MH, Jameel S. An Indian strain of hepatitis E virus (HEV): cloning, sequence, and expression of structural region and antibody responses in sera from individuals from an area of high-level HEV endemicity. J Clin Microbiol. 1995;33(10):2653-9.

4. Huang YW, Opriessnig T, Halbur PG, Meng XJ. Initiation at the third in-frame AUG codon of open reading frame 3 of the hepatitis $E$ virus is essential for viral infectivity in vivo. J Virol. 2007:81(6):3018-26.

5. Tam AW, Smith MM, Guerra ME, Huang CC, Bradley DW, Fry KE, Reyes GR. Hepatitis E virus (HEV): molecular cloning and sequencing of the full-length viral genome. Virology. 1991;185(1):120-31.

6. Meng XJ, Purcell RH, Halbur PG, Lehman JR, Webb DM, Tsareva TS, Haynes JS, Thacker BJ, Emerson SU. A novel virus in swine is closely related to the human hepatitis E virus. Proc Natl Acad Sci U S A. 1997; 94(18):9860-5.

7. Hsieh SY, Meng XJ, Wu YH, Liu ST, Tam AW, Lin DY, Liaw YF. Identity of a novel swine hepatitis E virus in Taiwan forming a monophyletic group with Taiwan isolates of human hepatitis E virus. J Clin Microbiol. 1999;37(12):3828-34.

8. Feagins AR, Opriessnig T, Huang YW, Halbur PG, Meng XJ. Cross-species infection of specific-pathogen-free pigs by a genotype 4 strain of human hepatitis E virus. J Med Virol. 2008;80(8):1379-86.

9. Feagins AR, Opriessnig T, Guenette DK, Halbur PG, Meng XJ. Detection and characterization of infectious hepatitis $E$ virus from commercial pig livers sold in local grocery stores in the USA. J Gen Virol. 2007;88(Pt 3):912-7.

10. Tei S, Kitajima N, Takahashi K, Mishiro S. Zoonotic transmission of hepatitis $E$ virus from deer to human beings. Lancet. 2003;362(9381):371-3.

11. Rein DB, Stevens GA, Theaker J, Wittenborn JS, Wiersma ST. The global burden of hepatitis E virus genotypes 1 and 2 in 2005. Hepatology. 2012; 55(4):988-97.

12. Dalton HR, Bendall $R$, ljaz S, Banks M. Hepatitis E: an emerging infection in developed countries. Lancet Infect Dis. 2008;8(11):698-709.

13. Aggarwal R, Krawczynski K. Hepatitis E: an overview and recent advances in clinical and laboratory research. J Gastroenterol Hepatol. 2000;15(1):9-20.

14. Khuroo MS, Kamili S. Aetiology, clinical course and outcome of sporadic acute viral hepatitis in pregnancy. J Viral Hepat. 2003;10(1):61-9.

15. Kumar A, Beniwal M, Kar P, Sharma JB, Murthy NS. Hepatitis E in pregnancy. Int J Gynaecol Obstet. 2004:85(3):240-4

16. Shukla P, Nguyen HT, Torian U, Engle RE, Faulk K, Dalton HR, Bendall RP, Keane FE, Purcell RH, Emerson SU. Cross-species infections of cultured cells by hepatitis E virus and discovery of an infectious virus-host recombinant. Proc Natl Acad Sci U S A. 2011;108(6):2438-43.

17. Shukla P, Nguyen HT, Faulk K, Mather K, Torian U, Engle RE, Emerson SU. Adaptation of a genotype 3 hepatitis $E$ virus to efficient growth in cell culture depends on an inserted human gene segment acquired by recombination. J Virol. 2012;86(10):5697-707.

18. Tanaka T, Takahashi M, Takahashi H, Ichiyama K, Hoshino Y, Nagashima $\mathrm{S}$, Mizuo $\mathrm{H}$, Okamoto $\mathrm{H}$. Development and characterization of a genotype 4 hepatitis $\mathrm{E}$ virus cell culture system using a HE-JF5/15F strain recovered from a fulminant hepatitis patient. J Clin Microbiol. 2009:47(6):1906-10.

19. Huang YW, Haqshenas G, Kasorndorkbua C, Halbur PG, Emerson SU, Meng XJ. Capped RNA transcripts of full-length cDNA clones of swine hepatitis $\mathrm{E}$ virus are replication competent when transfected into Huh7 cells and infectious when intrahepatically inoculated into pigs. J Virol. 2005;79(3):1552-8

20. Cordoba L, Feagins AR, Opriessnig T, Cossaboom CM, Dryman BA, Huang YW, Meng XJ. Rescue of a genotype 4 human hepatitis E virus from cloned CDNA and characterization of intergenotypic chimeric viruses in cultured human liver cells and in pigs. J Gen Virol. 2012:93(Pt 10):2183-94.

21. Huang F, Zhang W, Gong G, Yuan C, Yan Y, Yang S, Cui L, Zhu J, Yang Z, Hua $X$. Experimental infection of Balb/c nude mice with hepatitis $E$ virus. BMC Infect Dis. 2009;9:93.

22. Fu H, Wang L, Zhu Y, Geng J, Li L, Wang X, Bu Q, Zhuang H. Analysing complete genome sequence of swine hepatitis $E$ virus (HEV), strain CHNXJSW13 isolated from Xinjiang, China: putative host range, and disease severity determinants in HEV. Infect Genet Evol. 2011;11(3):618-23.

23. Huang FF, Haqshenas G, Guenette DK, Halbur PG, Schommer SK, Pierson FW, Toth TE, Meng XJ. Detection by reverse transcription-PCR and genetic characterization of field isolates of swine hepatitis $E$ virus from pigs in different geographic regions of the United States. J Clin Microbiol. 2002; 40(4):1326-32.

24. Nanda SK, Panda SK, Durgapal H, Jameel S. Detection of the negative strand of hepatitis $E$ virus RNA in the livers of experimentally infected rhesus monkeys: evidence for viral replication. J Med Virol. 1994;42(3): 237-40.

25. Baylis SA, Blumel J, Mizusawa S, Matsubayashi K, Sakata H, Okada Y, Nubling CM, Hanschmann KM. World Health Organization international standard to harmonize assays for detection of hepatitis E virus RNA. Emerg Infect Dis. 2013;19(5):729-35

26. Huang $F$, Hua X, Yang S, Yuan C, Zhang W. Effective inhibition of hepatitis $E$ virus replication in A549 cells and piglets by RNA interference (RNAi) targeting RNA-dependent RNA polymerase. Antivir Res. 2009;83(3):274-81. 
27. Okamoto H. Hepatitis E virus cell culture models. Virus Res. 2011;161(1): 65-77.

28. Aggarwal R, Kamili S, Spelbring J, Krawczynski K. Experimental studies on subclinical hepatitis $E$ virus infection in cynomolgus macaques. J Infect Dis. 2001;184(11):1380-5.

29. Panda SK, Ansari IH, Durgapal H, Agrawal $S$, Jameel $S$. The in vitrosynthesized RNA from a CDNA clone of hepatitis $E$ virus is infectious. J Virol. 2000;74(5):2430-7.

30. Zhu Y, Yu X, Zhang Y, Ni Y, Si F, Yu R, Dong S, Huang Y, Li Z. Infectivity of a genotype 4 hepatitis $E$ virus CDNA clone by intrahepatic inoculation of laboratory rats. Vet Microbiol. 2013;166(3-4):405-11.

31. Li TC, Suzaki Y, Ami Y, Tsunemitsu H, Miyamura T, Takeda N. Mice are not susceptible to hepatitis E virus infection. J Vet Med Sci. 2008;70(12): 1359-62.

Ready to submit your research? Choose BMC and benefit from:

- fast, convenient online submission

- thorough peer review by experienced researchers in your field

- rapid publication on acceptance

- support for research data, including large and complex data types

- gold Open Access which fosters wider collaboration and increased citations

- maximum visibility for your research: over $100 \mathrm{M}$ website views per year

At BMC, research is always in progress.

Learn more biomedcentral.com/submissions 